\title{
Prevalência de Salmonella sp em suínos abatidos em frígoríficos do Rio Grande do Sul ${ }^{1}$
}

\author{
Marjo Cado Bessa2 , Marisa da Costa ${ }^{3}$ e Marisa Cardoso 4
}

\begin{abstract}
Bessa M.C., Costa M. \& Cardoso M. 2004. [Prevalence of Salmonella sp. carrier pigs in slaughterhouses of Rio Grande do Sul, Brazil.] Prevalência de Salmonella sp em suínos abatidos em frígoríficos do Rio Grande do Sul. Pesquisa Veterinária Brasileira 24(2):80-84. Depto Medicina Veterinária Preventiva, Faculdade de Veterinária, Universidade Federal do Rio Grande do Sul, Av. Bento Gonçalves 9090, Porto Alegre, RS 91540-000, Brazil. E-mail: mcardoso@vortex.ufrgs.br

This study aimed to determine the prevalence of Salmonella positive pigs at slaughterhouses under federal inspection in Rio Grande do Sul, Brazil. Samples of feces and lymph nodes of 300 animals were collected in three different slaughterhouses, and submitted to bacteriological analysis. The prevalence of Salmonella carrier animals was $55.66 \%$ being $17.6 \%$ of the animals Salmonella positive in lymph nodes, $18.3 \%$ in feces and $19.6 \%$ in both materials. Twenty-six different serovars were identified among 226 Salmonella isolates. The most prevalent serovars were: Typhimurium $(24.3 \%$, Agona $(19.9 \%$, Derby $(13.2 \%)$ e Bredeney $(12 \%$. These results point out the need of control programs to reduce the prevalence of carrier pigs at slaughter.
\end{abstract}

INDEX TERMS: Salmonella, swine, lymph nodes, feces.

RESUMO.- Este estudo foi realizado com o objetivo de determinar a prevalência de Salmonella sp em suínos abatidos em frigoríficos sob inspeção federal no Rio Grande do Sul. Amostras de fezes e linfonodos foram coletadas em três diferentes frigoríficos no Estado. A partir da análise microbiológica das amostras de 300 animais, encontrou-se uma prevalência de Salmonella sp de $55,66 \%$ com $17,6 \%$ de isolamentos a partir dos linfonodos, $18,3 \%$ das fezes e $19,6 \%$ em ambos os materiais. Foram identificados 26 sorovares diferentes em 226 isolados de Salmonella sp. Os sorovares mais prevalentes foram: Typhimurium $(24,3 \%$, Agona $(19,9 \%$, Derby $(13,2 \%$ e Bredeney $(12 \%$. Estes resultados indicam a necessidade de implementar programas de controle com o objetivo de diminuir a prevalência de animais portadores ao abate.

TERMOS DE INDEXAÇÃO: Salmonella, suínos, linfonodos, fezes.

\footnotetext{
${ }^{1}$ Recebido em 1 de junho de 2001.

Aceito para publicação em 20 de fevereiro de 2004

2 Mestre em Microbiologia Agrícola e do Ambiente, UFRGS.

3 Depto Microbiologia, Instituto de Ciências Básicas da Saúde, UFRGS.

${ }^{4}$ Depto Medicina Veterinária Preventiva, Faculdade de Veterinária, UFRGS, Av. Bento Gonçalves 9090, Porto Alegre, RS 91540-000. E-mail: mcardoso@ vortex.ufrgs.br
}

\section{INTRODUÇÃO}

A qualidade microbiológica dos alimentos ingeridos pela população é um aspecto crucial para a saúde pública. Entre os microrganismos importantes para a segurança alimentar, a Salmonella tem se destacado como causadora de toxinfecções alimentares. Os produtos de origem avícola têm sido os mais comumente relacionados a surtos desta natureza em humanos. Entretanto, a contaminação da carne suína também pode vir a oferecer risco à população, conforme já relatado anteriormente (Wegener \& Bager 1997). A presença dessa bactéria em produtos de origem suína também é de importância para competir no mercado, que apresenta uma crescente exigência em relação à qualidade dos produtos.

Em decorrência disso, é necessário implementar programas de controle de Salmonella em rebanhos, bem como em pontos críticos da produção e do processamento dos alimentos de origem suína (Carlson \& Blaha 1998, Letellier et al. 1999). Para isso, é importante conhecer a prevalência, a distribuição e os sorovares de Salmonella presentes em suínos levados ao abate.

0 presente estudo objetivou determinar a prevalência de Salmonella sp em suínos levados ao abate em frigoríficos sob inspeção federal no Rio Grande do Sul, através da análise bacteriológica dos linfonodos mesentéricos e fezes desses animais. 


\section{MATERIAL E MÉTODOS}

Amostras. 0 tamanho de amostra mínima necessária para a determinação da prevalência de animais abatidos no Estado do Rio Grande do Sul (RS) e portadores de Salmonella sp foi calculado pelo programa EPI-Info (1996). Para tanto, foram fornecidos os seguintes parâmetros: número de animais abatidos sob inspeção federal no Estado (5.500.000/ano); prevalência estimada 10\%(Weiss et al. 1999); intervalo de confiança de $95 \%$ precisão absoluta de $5 \%$

Materiais de 300 suínos clinicamente normais foram amostrados em três diferentes frigoríficos sob inspeção federal no RS, entre setembro de 1999 ejulho de 2000. Estes frigoríficos foram escolhidos de forma aleatória e conforme a disposição dos mesmos em participar do estudo. Eles estão situados em três regiões representativas do Estado: Serra, Vale do Taquari e Noroeste. Os animais abatidos nestes frigoríficos procediam de granjas localizadas em diversos municípios no Estado do Rio Grande do Sul e constituíam-se, na sua maioria, de produtores em sistema de integração com a empresa.

Cada frigorífico foi visitado em 4 diferentes ocasiões, perfazendo 12 visitas. A amostragem era feita de forma que a primeira carcaça fosse selecionada ao acaso, e as 24 restantes escolhidas em um intervalo calculado a partir da divisão do número previsto de animais a serem abatidos, pelo número de amostras a serem colhidas. De cada animal eram retiradas as vísceras abdominais, colocadas em bandejas individuais e levadas a um local anexo à linha de abate, onde era feita a retirada de linfonodos mesentéricos e de um fragmento do intestino. Em seguida, as amostras eram colocadas em sacos plásticos individuais, identificadas e conservadas sob refrigeração para serem transportadas até o laboratório, onde eram processadas em até 24 horas.

Processamento das amostras. Foram pesados, separadamente, $25 \mathrm{~g}$ de conteúdo intestinal e linfonodos mesentéricos que, após acrescidos de $225 \mathrm{ml}$ de água peptonada tamponada e triturados em homogeneizador (Stomacher, Interscience), foram incubados a $37^{\circ} \mathrm{C}$ por 24 horas (etapa de pré-enriquecimento). Alíquotas de $1 \mathrm{ml} \mathrm{e}$ $0,1 \mathrm{ml}$ de cada amostra foram inoculadas, respectivamente, em $9 \mathrm{ml}$ de caldo Tetrationato Müller-Kauffmann e em $9,9 \mathrm{ml}$ de caldo Rappaport-Vassiliadis, e incubadas em banho-maria a $42^{\circ} \mathrm{C}$ por 24 horas. De cada tubo de enriquecimento seletivo, alíquotas foram semeadas em ágar Xilose Lisina Tergitol-4 (XLT4) e ágar Verde Brilhante Vermelho de Fenol Lactose Sacarose (BPLS) com Novobiocina 0,004\% Ambos os meios foram incubados por $24-48$ horas a $37^{\circ} \mathrm{C}$. Colônias suspeitas nos meios seletivos foram submetidas a provas bioquímicas e sorológica, com soro Salmonella Polivalente Somático (Probac), conforme Quinn et al. (1999). Todas as amostras de Salmonella isoladas foram enviadas para sorotipificação na Fundação Instituto Oswal do Cruz, Rio de Janeiro.

Análise estatística. A análise estatística foi realizada através do teste Qui-quadrado (SPSS 1998) com valores significantes para todas as análises de $a=0,05$. 0 intervalo de confiança (IC) das prevalências encontradas foi calculado conforme Smith (1995).

\section{RESULTADOS E DISCUSSÃO}

No passado, os produtos de origem suína estiveram menos freqüentemente implicados como fonte de surtos de toxinfecção alimentar causados por Salmonella em humanos. Entretanto, após um surto ocorrido na Dinamarca, onde a fonte pode ser traçada até produtos suínos (Wegener \& Bager 1997), a situação mundial tem se modificado. A partir da Dinamarca, iniciou-se um programa de controle que passou a ser adotado pela maioria dos países produtores e exportadores de produtos suínos.
No Brasil, a ocorrência de Salmonella em suínos sadios já havia sido relatada por Neiva (1946) e Lázaro et al. (1997). No Rio Grande do Sul, Weiss et al. (1999) e Michael (2000) isolaram Salmonella sp em granjas de terminação de suínos; entretanto, não determinaram a prevalência de animais positivos nos rebanhos.

Na literatura é possível observar que os estudos de prevalência são realizados, mais freqüentemente, com dados obtidos a partir de linfonodos mesentéricos, uma vez que esses são considerados indicadores do estado de portador do animal (Damman et al. 1999). Por outro lado, as fezes têm sido amostradas, principalmente em estudos conduzidos em granjas, e demonstram o estado de excretor dos animais (Davies et al. 1998). No frigorífico, o conteúdo intestinal pode ser fonte importante de contaminação cruzada das carcaças (Schwartz 2000). Por esta razão, optou-se no presente estudo pela coleta, tanto dos linfonodos mesentéricos, como do conteúdo intestinal para determinação da prevalência de animais positivos ao abate.

Dos 300 suínos amostrados, foi possível isolar Salmonella sp em 167 , resultando numa prevalência de $55,66 \%$ (IC: $50,04-61,28$ ) de animais positivos no momento do abate. Dentre esses animais, 53 apresentavam Salmonella apenas nos linfonodos mesentéricos, 55 apenas no conteúdo intestinal e 59 em ambos os materiais colhidos (Quadro 1). Desta forma, foi possível calcular a prevalência de animais positivos, isoladamente, em linfonodos e fezes como sendo 17,6\%(IC: 13,34-21,97) e 18,3\% (IC: 13,95-22,70), respectivamente. Por sua vez, a prevalência de animais que foram positivos em ambos os materiais amostrados foi $19,6 \%$ (IC: 15,16-24,15). Ainda, se considerarmos separadamente os dois materiais analisados, 37,3\%(IC: $32,41-43,39)$ dos animais apresentavam Salmonella sp nos linfonodos mesentéricos e 37,9\%(IC: 31,83-42,77) nas fezes.

Resultados próximos foram observados por Jayarao et al. (1990) em Budapeste, e Damman et al. (1999) nos Estados Unidos, que encontraram $48 \%$ e $67,6 \%$ respectivamente. De forma geral, constata-se uma grande variação nas prevalências de Salmonella em suínos relatadas na literatura, indo desde 3,5\%até $67,6 \%$ Este fato pode estar relacionado não só com possíveis diferenças nos índices de portadores, devido ao tipo de exploração e fatores regionais, como pela influência do método de amostragem realizada nos referidos estudos.

Quadro 1. Número de animais, linfonodos mesentéricos e fezes positivos para Salmonella sp nos frigoríficos A, B e C, localizados no Rio Grande do Sul

\begin{tabular}{|c|c|c|c|c|c|}
\hline \multirow[t]{2}{*}{ Frigorífico } & \multicolumn{5}{|c|}{$\mathrm{N}^{0}$ positivos } \\
\hline & $\begin{array}{c}\text { Animais } \\
\text { analisados }\end{array}$ & Animais & Fezes & $\mathrm{LN}^{1}$ & $\mathrm{LN}$ e $\mathrm{F}^{2}$ \\
\hline$A$ & 100 & $64^{a}$ & $17^{a}$ & $23^{a}$ & $24^{a}$ \\
\hline B & 100 & $57^{a b}$ & $22^{a}$ & $10^{b}$ & $25^{a}$ \\
\hline C & 100 & $46^{b}$ & $16^{a}$ & $20^{a}$ & $10^{b}$ \\
\hline Total & 300 & 167 & 55 & 53 & 59 \\
\hline $\begin{array}{l}1 \text { LN = Linfo } \\
2 \text { F= Fezes. } \\
a, b \text { Letras dif } \\
\text { ficativa ( } p\end{array}$ & na mesn & ha sig & e & $\mathrm{di}$ & ani- \\
\hline
\end{tabular}

Pesq. Vet. Bras. 24(2):80-84, abr./jun. 2004 
No Brasil, Neiva (1946) pesquisou a o corrência de Salmonella em suínos portadores, encontrando $41,5 \%$ de Salmonella no conteúdo intestinal e nos linfonodos mesentéricos. Lázaro et al. (1997) encontraram 34,8\% de Salmonella nas amostras de linfonodos e tonsilas. No Rio Grande do Sul, encontrou-se, anteriormente, ocorrência em torno de 10\%em conteúdo intestinal e linfonodos mesentéricos (Weiss et al. 1999).

Pela análise dos resultados obtidos (Quadro 1) verificou-se um elevado número de suínos portadores de Salmonella em cada frigorífico, havendo significativamente $(p=0,008)$ maior número de animais positivos no frigorífico $A$ em comparação ao frigorífico $\mathrm{C}$. Analisando o número de animais de acordo com o material onde se encontrou Salmonella sp, observa-se que houve menor número de isolados $(p=0,008)$ nos linfonodos do frigorífico $B$ e nos linfonodos e fezes do frigorífico $C$. Observou-se, também, grande variabilidade $(p=0,008)$ nos índices de isolamentos de Salmonella entre os tipos de materiais coletados.

$\mathrm{Na}$ Fig. 1, pode-se verificar a diferença de isolamentos em cada coleta por frigorífico, constatando-se uma variação de isolamentos entre coletas dentro do mesmo frigorífico. Percebe-se que há uma variação no número de isolamentos em cada tipo de amostra com relação às coletas $(p=0,0001)$ nos Frigoríficos $A$ e B. Na quarta coleta no frigorífico A ocorreu diminuição significativa $(p=0,0001)$ do número total de isolamentos de Salmonella em relação às demais coletas. Neste dia, observou-se que al guns lotes apresentavam altos índices de condenação por pneumonia, o que leva a supor que possa ter havido algum tipo de tratamento prévio destes animais com antimicrobianos, que possivelmente prejudicaram o isolamento de Salmonella no laboratório. Fato semelhante foi observado por Michael (2000), que fal hou ao tentar recuperar Salmonella sp. De fezes provenientes de animais tratados com antimicrobianos.

No frigorífico $\mathrm{C}$, observou-se variação no número de isolamentos entre as coletas, mas não com diferença significativa $(p=0,058)$. Desta forma foi possível constatar que, além de apresentar os menores índices de isolamento de Salmonella, em comparação com os outros frigoríficos, encontrou-se um perfil homogêneo nas diferentes visitas realizadas.

Supõe-se que a prevalência de Salmonella em suínos abatidos

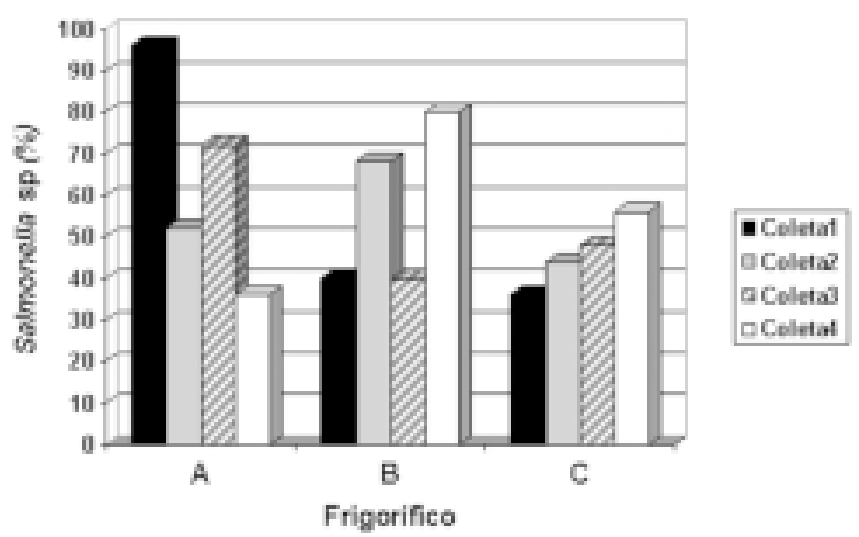

Fig. 2. Porcentagem de Salmonella sp isoladas em três frigoríficos ( $A$, B e C) localizados no Rio Grande do Sul.
Quadro 2. Distribuição de 226 amostras de Salmonella sp isoladas de fezes e linfonodos mesentéricos de suínos abatidos em três frigoríficos no Rio Grande do Sul, de acordo com o sorovar

\begin{tabular}{lcccc}
\hline \multirow{2}{*}{ Sorovares } & \multicolumn{3}{c}{ Frigoríficos } & Total \\
\cline { 2 - 4 } & A & B & C & \\
\hline Typhimurium & 6 & 33 & 16 & 55 \\
Agona & 18 & 9 & 18 & 45 \\
Derby & 9 & 21 & 0 & 30 \\
Bredeney & 25 & 0 & 2 & 27 \\
Panama & 5 & 7 & 1 & 13 \\
Newport & 1 & 2 & 4 & 7 \\
Tennessee & 5 & 0 & 1 & 6 \\
Anatum & 3 & 2 & 1 & 6 \\
(9,12:Iv:-) & 2 & 1 & 2 & 5 \\
Rissen & 4 & 0 & 0 & 4 \\
Enteritidis & 2 & 1 & 0 & 3 \\
Give & 1 & 0 & 2 & 3 \\
Montevideo & 2 & 1 & 0 & 3 \\
(3,10:eh:-) & 0 & 2 & 1 & 3 \\
Heidelberg & 0 & 2 & 0 & 2 \\
Infantis & 0 & 0 & 2 & 2 \\
London & 1 & 0 & 1 & 2 \\
Mbandaka & 0 & 0 & 2 & 2 \\
Havana & 1 & 0 & 0 & 1 \\
Ohio & 0 & 0 & 1 & 1 \\
Senftenberg & 1 & 0 & 0 & 1 \\
(6,7:6:-) & 1 & 0 & 0 & 1 \\
(0:3:10) & 0 & 0 & 1 & 1 \\
(4,5:-:1,7) & 0 & 0 & 1 & 1 \\
(4,5:-:1,2) & 0 & 1 & 0 & 1 \\
(0:4,5) & 1 & 0 & 0 & 1 \\
Total & 88 & 82 & 56 & 226 \\
& & & &
\end{tabular}

esteja associada a múltiplos fatores de risco presentes na granja, e ainda ao transporte, que poderiam aumentar a intensidade da contaminação do lote. 0 transporte e a espera do abate são provavelmente fatores importantes para a ocorrência de Salmonella no frigorífico (Morrow et al. 2000). Isto se deve a fatores como o estresse dos suínos portadores que ocorre durante o transporte, a superlotação e a espera antes do abate, que possibilita a excreção de bactérias eventual mente presentes no conteúdo intestinal desses animais, tornando-se fonte de contaminação para outros animais (Williams \& Newell 1970). Neiva (1946), Linton (1979) e Morrow et al. (1999) descreveram os suínos portadores como fonte primária de infecção, por abrigarem Salmonella no intestino e nos linfonodos, e como ponto fundamental para o controle da contaminação na linha de abate.

No presente estudo foram identificados 26 diferentess sorovares, em 226 amostras de Salmonella sp isoladas de 167 suínos portadores. Desses, sete não foram identificados por não expressarem o antígeno flagelar (Quadro 2).

Os sorovares mais prevalentes foram Typhimurium $(24,3 \%$, seguido por Agona $(19,9 \%$, Derby $(13,2 \%$ e Bredeney $(12 \%$. É importante enfatizar que não foi encontrado o sorovar Choleraesuis, mais adaptado aos suínos e que, geralmente, causa sintomas clínicos nos animais. Esse resultado foi similar ao de outros países, onde o sorovar Typhimurium foi o mais freqüentemente encontrado em suínos sadios (Kampelmacher 
et al. 1963, Di Guardo et al. 1992, Käsbohrer et al. 1997, Ganter et al. 1998, Kim et al. 2000). No Brasil, Peluffo et al. (1946) e Zebral et al. (1974) encontraram o sorovar Typhimurium como o mais freqüente em seus estudos. Neiva (1946) e Lázaro et al. (1997) isolaram Derby e Muenster, respectivamente, como os sorovares mais freqüentes, porém encontraram também Salmonella Typhimurium.

A predominância dos sorovares variou de um frigorífico para outro como é demonstrado no Quadro 2. Foram isolados 18 sorovares diferentes no frigorífico $\mathrm{A}$ e no frigorífico $\mathrm{B}$ e $\mathrm{C}$ foram isolados 12 e 16 sorovares diferentes, respectivamente.

0 sorovar Bredeney foi significativamente mais encontrado no frigorífico $A(p=0,0001)$, enquanto no frigorífico $B$ houve predominância significativa dos sorovares Typhimurium e Derby $(p=0,0001)$, em relação aos demais. Não existiu diferença significativa para os sorovares Agona $(p=0,1429)$, Anatum $(p=0,6035)$, Newport $(0,3636)$ e Panama $(p=0,1106)$ entre os frigoríficos, embora exista uma tendência, não comprovada estatisticamente, do predomínio de algum deles em um determinado frigorífico.

Considerando apenas os 59 animais positivos concomitantemente em linfonodos mesentéricos e fezes, observou-se que em 33 animais (56\% os so rovares encontrados nos dois materiais foram os mesmos, enquanto em 26 animais (44\% os sorovares foram diferentes. Entre os animais com o mesmo sorovar nas duas amostras, os sorovares Typhimurium, Agona e Derby foram os predominantes, concordando com o perfil de isolamentos do presente estudo. Entre os animais com sorovares diferentes em fezes e linfonodos não houve uma associação predominante.

Em estudos realizados por Neiva (1946) em amostras de fezes e linfonodos foi possível observar diferença de isolamentos de sorovares de Salmonella. Zebral et al. (1974) pesquisaram a presença de Salmonella em diferentes linfonodos de 59 suínos e encontraram diferentes sorovares num mesmo animal. Riley (1970) isolou, em três ocasiões, dois sorovares diferentes em amostras de fezese linfonodos num mesmo suíno. Michael (2000) encontrou 15 sorovares diferentes em animais de uma única granja de terminação, comprovando, desta forma, que nas granjas também podem ser encontradas infecções com múltiplos sorovares de Salmonella.

Correlacionando este estudo com anteriores realizados no RS, observa-se que não houve uma similaridade do sorovar mais prevalente com o encontrado por Weiss et al. (1999), que não isolou Salmonella Typhimurium. No entanto, os sorovares Agona, Bredeney, London, Mbandaka e Panama foram encontrados em ambos os estudos. Entretanto, como afirmado por Chung \& Frost (1969), os sorovares encontrados em suínos podem variar grandemente de acordo com as regiões ou a sazonalidade.

Alguns desses sorovares, como Senftenberg, Anatum, Agona, Infantis, Typhimurium, Derby, Mbandaka e Tennessee foram encontrados em rações pesquisadas no Brasil (Miranda et al. 1978, Fialho et al. 1985, Michael 2000). Isto faz supor que a Salmonella possa estar sendo introduzida no rebanho de suíno através da ração contaminada. Diversos autores já relataram que a Salmonella é transmitida ao animal principalmente através da alimentação, e que os linfonodos mesentéricos agem como uma barreira, tornando-se, mais tarde, fonte de contaminação para a carcaça e para o produto final (Kampelmacher et al. 1963, Costa et al. 1972, Wilcock \& Schwartz 1992, Damman et al. 1999, Schwartz 2000).

Além da Salmonella Typhimurium, os sorovares Derby, Bredeney, Anatum, Enteritidis e Agona têm sido os mais encontrados em suínos portadores no Brasil e no mundo. Vários autores já relataram pelo menos um desses sorovares como sendo 0 mais freqüente em seus estudos (Neiva 1946, Kampelmacher et al. 1963, Riley 1970, Costa et al. 1972, Zebral et al. 1974, Di Guardo et al. 1992, Davies et al. 1998, Weiss et al. 1999). Já entre os sorovares mais freqüentemente isolados em episódios de infecção alimentar em humanos no Brasil encontram-se Enteritidis, Typhimurium, Bredeney e Tennessee (Landgraf et al. 1985, Cauduro et al. 1986, Esper et al. 1998, Dias et al. 1999, Jakabi et al. 1999), constatando-se que existem al guns sorovares comuns a ambos os grupos, indicando assim a possibilidade do suíno ter papel importante na transmissão de salmonelose ao humano, mais do que 0 anteriormente suposto.

A identificação das amostras distribuídas segundo os grupos sorológicos, conforme consta no Quadro 3, evidencia uma nítida predominância de amostras pertencentes ao grupo $B$, representando $68,2 \%$ Este resultado foi semelhante a outros estudos usando amostras de linfonodos e fezes (Neiva 1946, Riley 1970, Caley 1972, Di Guardo et al. 1992, Käsboher et al. 1997, Weiss et al. 1999).

Nesse Quadro consta um número total de 193 isolamentos provenientes de 167 animais positivo, uma vez que, como referido anteriormente, em 26 ocasiões nas amostras de fezes e de linfonodos de um mesmo animal, isolaram-se sorovares diferentes de Salmonella sp.

Detectar Salmonella sp nos animais que chegam ao frigorífico significa um fator de risco, mas não pode ser interpretada como um índice de contaminação do produto final. Entretanto, maior será a dificuldade de controlar os pontos críticos na indústria, quanto maior for o índice de animais que chegarem portadores e/ou excretores de Salmonella no momento do abate. Por esta razão, o número de animais portadores que chega ao abate tem sido apontado como o primeiro ponto crítico do processamento, em relação a Salmonella.

Estudos enfatizando a epidemiologia de animais assintomáticos na granja podem levar a um melhor entendimento do ciclo da contaminação de Salmonella nos suínos. Portanto, é possível concluir que a redução do nível de carcaças contaminadas na indústria será al cançada pela identificação e controle das fontes de contaminação em todos os estágios de produção (Carlson \& Blaha 1998, Letellier et al.1999).

\section{REFERÊNCIAS}

Caley J.E. 1972. Salmonella in pigs in Papua New Guinea. Aust. Vet. J. 48:601-604.

Carlson A.R. \& Blaha T. 1998. On-farm Salmonella-control procedureswhat is known? Investigations into zoonotic Salmonella in Minnesota, p.141-147. In: Swine Disease Conference for Swine Practitioners, Ames, lowa.

Cauduro P.F., Mezzani A. \& Dias C.A.G. 1986. Isolamento de Salmonella Tennessee em fezes humanas no Rio Grande do Sul. Revta Microbiol. 17(2):113-159. 
Chung G.T. \& Frost A.J. 1969. The occurrence of Salmonella in slaughtered pigs. Aust. Vet. J. 45:350-353.

Costa G.A., Hofer E., Costa M.D.M., Silva J.A.H., Santos J.V. \& Doria J.D. 1972. Sobre o isolamento de salmonelas de gânglios linfáticos de suínos abatidos no matadouro da cidade de Salvador, Bahia. Mem. Inst. Osw. Cruz 70(3):417-431.

Damman D., Bahnson P.B. \& Weigel R.M. 1999. An estimate of Salmonella prevalence on Illinois swine farms using mesenteric lymph node cultures, p.23-125. In: 3rd International Symposium on the Epidemiology and Control of Salmonella in Pork, Washington, DC.

Davies P.R., Bovee F.G., Funk J.A., Morrow W.E., Jones F.T. \& Deen J. 1998. Isolation of Salmonella serotypes from feces of pigs raised in a multiplesite production system. J. Am. Med. Vet. Assoc. 212(12):1925-1929.

Dias R.S., Carmo L.S. \& Silva M.C.C. 1999. Surto de toxinfecção alimentar causado pela ação simultânea de enterotoxina estafilocócica e Salmonella Enteritidis. Revta Inst. Adolfo Lutz, São Paulo, 58(1):7-11.

Di Guardo G., Fontanelli G., Panfili G., Condoleo, Grossi L., Brozzi A.M. \& Bozzano A.I. 1992. Occurrence of Salmonella in swine in the Latium Region (Central Italy) from 1980 to 1989: a retrospective study. Vet. Quarterly 14(2):62-65.

Epi-info. 1996. Versão 6.04. World Health Organization, Geneva.

Esper M.R.N.R., Freitas A.M., Fernandes S.A., Neme S.N., Tavechio A.T. Romão M.M. \& Café M.L.1998. Salmonella: Sorotipos identificados das cepas isoladas de pacientes hospitalizados e não hospitalizados, na região de Presidente Prudente, SP, no período de 1978-1997. Revta Inst. Adolfo. Lutz, São Paulo, 57(2): 45-50.

Fialho E. T., Sobestiansky J., Brito J. R. F., Bellaver C. \& Wentz I. 1985. Análise proximal e ocorrência de salmonelas em alimentos e concentrados protéicos utilizados em rações de suínos. Embrapa Suínos e Aves, Concórdia, SC, 87:1-4.

Ganter M., Muller K., Tegeler R. \& Friedel K. 1998. Prevalence of Salmonella in finishing pigs of Northwest Germany, p.70. In: 15th IPVS Congress, Birmingham, England.

Jakabi M., Buzzo A.A., Ristori C.A., Tavechio A.T., Sakuma H., Paula A.M.R. \& Gelli D.S. 1999. Observações laboratoriais sobre surtos alimentares de Salmonella sp., ocorridos na grande São Paulo, no período de 19941997. Revta Inst. Adolfo Lutz, Asão Paulo, 58(1):47-51.

Jayarao B.M., Lászlo V.G., Csák K., Milch H., Kostyák A., Kovács S., Domján H. \& Biró G. 1990. Epidemiology of Salmonella Derby strains isolated from swine, pork and pork products. Acta Vet. Hung. 38(1):25-32.

Kampelmacher E.H., Guinée P.A., Hofstra K. \& Van Keulen A. 1963. Further studies on Salmonella in slaughterhouses and in normal slaughter pigs. Zentralbl. VetMed., Reihe B, 10:2-27.

Käsbohrer A.M., Geue L., Staak C.H., Steinbach G., Rabsch W., Helmuth R., Blaha T.H. \& Protz D.1997. Prevalence of Salmonellae in German slaughter pigs as detected by cultural, serological and PCR techniques, p.315320. In: Salmonella and Salmonellosis. France.

Kim B.H., Kim K.T., Woo Y.K. \& Cho G.J. 2000. Prevalence of Salmonella spp in lymph nodes of slaughtered pigs in Korea, p.220. In: 16th International Pig Veterinary Society Congress, Melbourne, Austrália.

Landgraf M., Gonçalves J.A. \& Falcão D.P. 1985. Surto de toxinfecção alimentar por Salmonella Bredeney. Revta Saúde Pública, Rio de J., 19:9293.

Lázaro N. S., Tibana A. \& Hofer E. 1997. Salmonella spp in healthy swine and in abattoir environments in Brazil. J. Food Protection 60(9):10291033.

Letellier A., Messier S. \& Quessy S. 1999. Prevalence of Salmonella spp. and Yersinia enterocolitica in finishing swine at Canadian abattoirs. J. Food Protection 62(1):22-25.

Linton A.H. 1979. Salmonellosis in pigs. Brit. Vet. J. 135(2)109-112.

Michael G.B. 2000. Comparação de diferentes etapas de enriquecimento seletivo no isolamento de Salmonella sp. a partir de fezes de suínos de terminação. Dissertação (Mestrado), Programa de Pós-Graduação em Microbiologia Agrícola e do Ambiente, Universidade Federal do Rio Grande do Sul, Porto Alegre.114p.

Miranda J.B.N., Pessoa G.V.A., Irino K. \& Calzada C.T. 1978. Ocorrência de Salmonella em farinhas utilizadas como matéria-prima na composição de rações de animais. Revta Inst. Adolfo Lutz, São Paulo, 38(2):157-160.

Morrow W.E.M., Davies P.R., See T., Eisemann J., Zering K., Kihlstrom S. \& Karli K. 1999. Prevalence of Salmonella spp. in the feces on farm and ceca at slaughter for a cohort of finishing pigs, p.155-157. In: 3rd International Symposium on the Epidemiology and Control of Salmonella in Pork, Washington, DC.

Morrow W.E.M., Davies P.R., See T., Eisemann J., Zering K., Kihlstrom S. \& Karli K. 2000. The prevalence of Salmonella spp in feces on the farm and in ceca at slaughter, p.207. In: 16th Internacional Pig Veterinary Society Congress, Melbourne, Australia.

Neiva C. 1946. Incidência de salmonelas em suínos. Mem. Inst. Butantan 7:430-435.

Peluffo C.A., Bier O., Amaral J.P. \& Biocca E. 1946. Estudos sobre as salmoneloses em São Paulo. Mem. Inst. Butantan 19:211-228.

Quinn P.J., Carter M.E., Markey B. \& Cartey G.R. 1999. Clinical Veterinary Microbiology. Mosby's, London. 648 p.

Riley M.G.I. 1970. The incidence of Salmonella in normal slaughtered pigs. Aust. Vet. J. 46:40-43.

Schwartz K.J. 2000. Salmonellosis, p.535-551. In: Straw B. E., D'Allaire S., Mengeling W.L. \& Taylor D.J.(ed). Diseases of Swine. 8th ed. Iowa State Universty, Ames.

Smith R.D. 1995.Veterinary Clinical Epidemiology: A problem-oriented approach. 1st ed. CRC, London.

SPSS-Statistical Package for the Social Sciences. 1998. Versão 8.0. Chicago, McGraw-Hill Book Company, p.145-159.

Wegener H. C. \& Bager F. 1997. Pork as a source of human salmonellosis, p. 3-8. In: 2 International Symposium on Epidemiology and Control of Salmonella in Pork, Copenhagen.

Weiss L. H. N., Nonnig R., Cardoso M. \& Costa M. 1999. Occurrence of Salmonella in finishing pigs in south Brazil, p. 184-185. In: 2nd International Symposium on Epidemiology and Control of Salmonella in Pork, Washington, DC.

Wilcock B. P. \& Schwartz K. J. 1992. Salmonellosis, p. 570-580. In: Lehman A. D., Shaw B. E., Mengelin L. W., D'allaire S. \& Taylor D. J. (ed) Diseases of swine. 7th ed. lowa State University, Ames.

Williams L. P. \& Newell K. W. 1970. Salmonella excretion in joy-riding pigs. A. J. Pig Health 60(5):926-929.

Zebral A.A., Freitas C.A. \& Hofer E. 1974. Ocorrência de Salmonella em gânglios linfáticos de suínos aparentemente normais, abatidos no matadouro de Santa Cruz, cidade do Rio de Janeiro, Guanabara. Mem. Inst. Oswaldo Cruz 72(3):223-235. 